\author{
Jennifer McDevitt \\ University of Alberta, Edmonton, AB, Canada
}

\title{
Educating and Empowering Teen Activists in Public Libraries: A Case Study of the Impact of Reading on Young Adult Social Justice Actions (Paper)
}

\begin{abstract}
Résumé:
This participatory case study, which consisted of a co-designed virtual program through the Camrose Public Library, investigates how teen readers engage with the social justice themes in YA fiction, how and if they find these themes useful for understanding and engaging in activism on their own, and the influence of public library programming on these actions. I approached my research from a teen-centred perspective, inviting the youth who participated to make adjustments to each stage of the process. My research design, data collection, and data analysis were informed by critical ethnography as theory and reader-response theory. This case study found that, on their own, neither social activism narratives nor library programs motivate teens to conduct social justice actions; instead, they contribute to a network of learning opportunities and information that leads to teens becoming motivated to make a difference in their communities. Thus, public libraries can provide teen programming that uses social activism narratives and collaborative discussions to teach teens more about social justice issues, show them how to get involved in social justice movements, and instill in them the confidence to do so.
\end{abstract}

\section{Introduction}

In recent years, young adult (YA) fiction has turned to social justice issues and activism. The 'social problem' narratives dealing with serious topics like violence, substance abuse, sexual assault, and racial justice that have populated YA fiction since its beginnings have expanded to include 'social activism' narratives. I define social activism narratives broadly as any work of fiction (book, video game, television show, interactive fiction, etc.) that centers around a social justice issue, imagines a world where young adults are revolutionary heroes, and depicts the characters fighting to make change in their society, often but not always via protests (adapted from Ventura, 2011; Winters, 2019). At the same time as this evolution in YA literature, the discussion of social responsibility in librarianship has begun to include social justice (Gorham, 
Taylor \& Jaeger, 2016; American Library Association, 2016). To investigate the relationships between social activism narratives in YA fiction, real actions taken by teens who read that fiction, and the influence of public library programming on teens, I conducted a participatory case study in partnership with the Camrose Public Library (CPL). My aim was to discover how public libraries might use YA fiction featuring social activism narratives in their programs to engage with youth and empower them to actively create change in their communities. Thus, this research explores the following questions:

- How might reading social activism narratives and discussing them in the context of real-world issues affect young adults' thinking about and motivation to conduct social justice actions?

- How does acting as collaborators to design the library program and choose what to read affect the experience of the young adults participating in the program and their reactions to the media they read?

- How can public libraries create spaces where young adults can learn about and enact social justice actions through reading?

\section{Methodological and Theoretical Frameworks}

The design of this participatory case study follows from the work of LIS scholars who have built on the history of youth community engagement and youth activism to encourage YA librarians to consider teens as fully-realized people with concerns about social justice issues and to work directly with them when developing library services and programs (Coats, 2019; Lesko, 2019; Males, 2019; Rothbauer, 2019). In particular, it is predicated on the assertion of Agosto (2019) that YA librarianship should be based on a teen-centred approach, which focuses on asking teens what they need and want rather than analyzing texts in an attempt to determine what is best for them. This approach echoes the bottom-up nature of participatory research, which I used by considering the participants to be research partners. Participatory research encompasses a range of methods that aim to give research participants more power in the researcher-research relationship, most often when doing research for people who have been considered voiceless or powerless (Cornwall \& Jewkes, 1995; Nind, 2011). The lack of teen voice in library research is problematic; young adults deserve to be talked to and not just about (Moeller, Pettee, \& Leeper, 2011; Crawford Barniskis, 2013). Participating as research partners who are involved in making 
decisions about what will be researched, how data is made sense of, and what is done with the research ensures that teen voices are included to the extent that the teens want them included.

The research design and analysis was influenced by critical ethnography as theory and reader-response theory. Critical ethnography is critical theory in action, and the critical ethnographer "takes us beneath surface appearances, disrupts the status quo, and unsettles both neutrality and taken-for-granted assumptions by bringing to light underlying and obscure operations of power and control" (Madison, 2012, p. 5). Using critical ethnographic methods meant that I thought constantly about the power structures affecting my participants, especially the power I was and was not affording them myself. I tried to approach my own detailed recording of an experience as if it was unfamiliar to me, and using critical ethnography as theory meant I attempted to expose and disrupt power relationships that I and my participants experienced rather than simply describing them. Furthermore, reader-response theory shaped every aspect of my findings because I approached them with the assumption that readers actively participate in making meaning from texts. Rosenblatt (1995) argues that it is impossible for writers and readers to refrain from reading their own values into a work, as both they and the work are a part of "a scheme of values, a sense of a social framework" (p. 6). Teachers should, therefore, point out those value assumptions and encourage students to consider and criticize them. Rosenblatt's transactional theories of reading aim to have readers not only understand texts, but also understand the world and their place in it, and thus feel empowered to change it. Her belief in the transformative power of reading is foundational to this study, and I endeavoured to reflect it in my facilitation of the program sessions and to encourage my participants to reflect upon the ways they were actively engaging in creating the text.

\section{Research Design}

I recruited three youth (Jane, 14, she/her; Noah, 14, he/him; and Violet, 17, she/they) to participate as research partners and enlisted their input throughout the research process. The participants were invited to modify the research questions and to help build a library program centred around reading social activism narratives and conducting social justice actions. The program ran for about two months in the summer of 2020 via Google Meet. Based on their own interests and desires, the participants chose the material we read (We Set the Dark on Fire (2019) by Tehlor Kay Mejia, Missing in Action (2010) by Dean Hughes, and Flygirl (2009) by Sherri L. 
Smith), the social justice issues we focused on (immigration rights), and the social justice actions that the group undertook together (a digital poster). Following the conclusion of the program, I used my methodological and theoretical frameworks to analyze data collected via field notes taken during the program and during individual discussions with the participants. My research partners were invited to provide feedback on the data analysis after each stage, though they largely chose not to do so.

\section{Findings}

This case study fills a gap in evidence-based research into YA services (Bernier, 2019), and its findings agree with the limited amount of prior research into social-justice-related teen library programming, participatory research with teens, and the benefits of a teen-centred approach: the participants appreciated being listened to and felt included when given the opportunity for flexible decision-making (Agosto, 2019; Hoopes, 2018; Crawford Barniskis, 2013). I found that, on their own, neither social activism narratives nor library programs motivate teens to conduct social justice actions; instead, they contribute to a network of learning opportunities and information that leads to teens becoming motivated to make a difference in their communities. This finding was evidenced by Violet and Jane coming to the library program precisely because they were already motivated to conduct social justice actions and stating that they felt the program was a learning opportunity that provided them with the tools and confidence for social justice work. They were able to find more inspiration, and thus motivation, from the books we read when they had prior knowledge and experience that helped them relate the books to current events. Thus, public libraries can provide teen programming that uses social activism narratives and collaborative discussions to teach teens more about social justice issues, show them how to get involved in social justice movements, and instill in them the confidence to do so. The ability of libraries to accomplish this rests on a symbiotic relationship between inspiration, education, confidence, and motivation. For instance, rich discussions of a text help it to provide inspiration, and rich discussions rest on how much knowledge the readers are able to bring to the text. The more knowledge the reader has, whether that comes from prior experience or education within the program, the more confident they become. Having inspiration, education, and confidence leads to increased levels of motivation, while already being motivated leads to a desire to acquire more inspiration, education, and confidence. 
Flexibility is important when it comes to helping teens feel included; choices should be provided along with time to consider them and explanation of the rationale behind them. Expectations that are not flexible should be explicated in-depth as well so that teens understand why they exist and feel supported in achieving them. This finding is echoed in literature about YA library programs, YA literature, and youth civic spaces. Hoopes (2018) encourages librarians to develop the confidence of youth when it comes to social justice by listening to teens, talking about local issues with them, and modelling activism. Additionally, Boyd \& Darragh (2019) believe that YA literature can encourage social action projects when students are provided opportunities to choose what to read and what actions to take. My findings also fit into the framework for creating youth spaces provided by Richards-Schuster and Dobbie (2011), which includes providing dedicated adult allies, facilitating critical education and building skills for action, and integrating action and reflection. Overall, creating this kind of space revolves primarily around providing teen patrons with time and space to consider their choices carefully and making clear that they have an adult support system throughout the program. 


\section{Reference List:}

Agosto, D. E. (2019). Envisaging young adult librarianship from a teen-centered perspective. In Bernier (Ed.), Transforming Young Adult Services (2nd ed.) (p. 1-1xiv). ALA Neal-Schuman.

American Library Association. (2016, April 12). Office for diversity, literacy and outreach services: What we do. Retrieved from http://www.ala.org/aboutala/offices/diversity/what-we-do

Bernier, A. (Ed.). (2019). Transforming Young Adult Services (2nd ed.). ALA Neal-Schuman.

Boyd, A. S., \& Darragh, J. J. (2019). Reading for action: Engaging youth in social justice through young adult literature. Rowman \& Littlefield Publishers.

Coats, K. (2019). Diverse identity in anxious times: Young adult literature and contemporary culture. In Bernier (Ed.), Transforming Young Adult Services (2nd ed.) (p. 1xv-lxxv). ALA Neal-Schuman.

Cornwall, A., \& Jewkes, R. (1995). What is participatory research? Social Science \& Medicine, 41(12), 1667-1676.

Crawford Barniskis, S. (2013). Embedded, participatory research: Creating a grounded theory with teenagers. Evidence Based Library and Information Practice, 8(1), 47-58.

Gorham, U., Taylor, N.G. \& Jaeger, P. T. (2016). Perspectives on Libraries As Institutions of Human Rights and Social Justice. Emerald Group Publishing Limited.

Hoopes, E. (2018). Social Justice Symposium for Teens. Public Libraries, 57(1), 27-28.

Hughes, D. (2010). Missing in Action. Atheneum Books for Young Readers.

Lesko, W. S. (2019). Beyond coaching: Copiloting with young adults. In Bernier (Ed.), Transforming Young Adult Services (2nd ed.) (p. 1897m-1897t). ALA Neal-Schuman.

Madison, D. S. (2012). Critical ethnography : method, ethics, and performance. 2nd ed. SAGE.

Males, M. (2019). Tribalism versus citizenship: Are youth increasingly unwelcome in libraries? In Bernier (Ed.), Transforming Young Adult Services (2nd ed.) (p. 1898e-1898q). ALA Neal-Schuman.

Mejia, T. K. (2019). We Set the Dark on Fire. Katherine Tegen Books.

Moeller, R., Pattee, A., \& Leeper, A. (2011). The young adult voice in research about young 
adults. Journal of Research on Libraries and Young Adults. Retrieved from http://www.yalsa.ala.org/jrlya/2011/11/the-young-adult-voice-in-research-about-young-ad ults/

Nind, M. (2011). What is participatory research? [Streaming video]. Retrieved from SAGE Research Methods.

Richards-Schuster, K., \& Dobbie, D. (2011). Tagging walls and planting seeds: Creating spaces for youth civic action. Journal of Community Practice, 19(3), 234-251.

Rosenblatt, L. M. (1995). Literature as Exploration. 5th ed. Modern Language Association of America.

Rothbauer, P. M. (2019). Imagining today's young adults in LIS: Moving forward with critical youth studies. In Bernier (Ed.), Transforming Young Adult Services (2nd ed.) (p. 1898r-1899d). ALA Neal-Schuman.

Smith, S. L. (2009). Flygirl. G.P. Putnam's Sons Books for Young Readers.

Ventura, A. (2011). Predicting a better situation? three young adult speculative fiction texts and the possibilities for social change. Children's Literature Association Quarterly, 36(1), $89-103$.

Winters, E. (2019). Young adult literature has a lot to say about social justice. America, 221(9), $44-45$. 